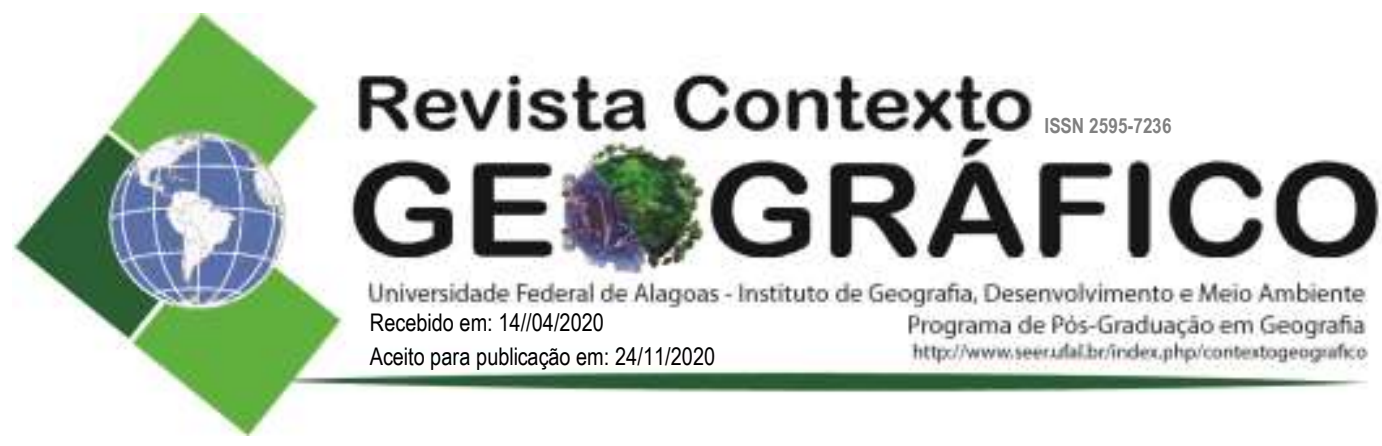

\title{
URBANIZAÇÃO DO CAMPO: ESTUDO DE CASO DA COMUNIDADE RURAL DE TRAÍRAS, MUNICÍPIO DE MACAÍBA - RN
}

\author{
Damião Ferreira da Silva Neto \\ Graduando em Engenharia Agronômica, Universidade Federal do Rio Grande do Norte \\ (UFRN), Natal, Rio Grande do Norte, Brasil \\ damiaoneto222@gmail.com
}

Adailton de Moura Costa

Graduado em Geografia Licenciatura, Universidade Federal do Rio Grande do Norte (UFRN),

Natal, Rio Grande do Norte, Brasil

dailto.costa2@gmail.com

João Paulo Teixeira Viana

Mestre em Ensino de Geografia, Universidade Federal do Rio Grande do Norte (UFRN), Natal,

Rio Grande do Norte, Brasil

jpviana25@yahoo.com

RESUMO - O espaço rural vem passando por modificações estruturais na medida em que este começa a passar por um processo de revalorização, a partir da década de 1980, após ter passado longo período de desvalorização, momento em que o Brasil iniciou seu processo de industrialização. Tais transformações têm trazido ao campo nova funcionalidade e ocupado a população rural em atividades não-agrícolas, e emergência de famílias pluriativas. As transformações do espaço rural não implicam somente na funcionalidade, mas têm ocorrido mudanças no espaço físico, com a melhoria da infraestrutura e dos serviços básicos, como também mudanças nos hábitos e na cultura da população rural, a descrição da comunidade e o levantamento das condições socioeconômicas locais. Como resultado, conseguimos identificar que vem ocorrendo melhorias na infraestrutura da comunidade em estudo, mas que ainda necessita de benfeitorias no setor social e econômico.

Palavras-chave: Espaço Rural; Famílias Pluriativas; Comunidade Traíras.

\section{URBANIZATION OF THE COUNTRYSIDE: CASE STUDY OF THE RURAL COMMUNITY OF TRAÍRAS, MUNICIPALITY OF MACAÍBA - RN}

\begin{abstract}
The rural space has been going through structural changes as it begins to go through a revaluation process, from the 1980 s on, after a long period of devaluation, when Brazil started its industrialization process. Such transformations have brought to the countryside new functionality and occupied the rural population in non-agricultural activities, and the emergence of pluriative families. The transformations of the rural space do not imply only in functionality, but there have been changes in the physical space, with the improvement of the infrastructure and basic services, as well as changes in the habits and culture of the rural population, the description of the community and the survey of local socioeconomic conditions. As a result, we have been able to identify that improvements have been taking place in the infrastructure of the community under study, but that it still needs improvements in the social and economic sector.
\end{abstract}

Keywords: Rural Space; Pluriative Families; Traitor Community. 


\section{INTRODUÇÃO}

Neste trabalho, abordaremos a urbanização do campo, bem como o surgimento de novas atividades no meio rural, atividades estas que trouxeram ao campo novas funções. Tais fenômenos vêm ocorrendo em diferentes lugares do País, sendo mais acentuado no Centro-Sul brasileiro, onde a modernização agrícola é bem mais avançada, devido a sua estrutura econômica decorrente do processo histórico brasileiro. No Nordeste se verifica também tais fenômenos, porém ocorre de uma forma menos intensa do que no Centro-Sul.

O estudo tem como base a comunidade rural de Traíras, município de Macaíba, Rio Grande do Norte, onde apontaremos como tal comunidade tem enfrentando estas modificações em sua estrutura socioeconômica. Torna-se de grande relevância para a ciência geográfica um estudo sistemático da urbanização do campo no nosso estado, como também um esboço, do surgimento de novas atividades econômicas, como forma de permanência das populações no meio rural. Estas preocupações evidenciam na medida em que os estudos relacionados à essa temática são poucos no Rio Grande do Norte, sendo está de grande relevância para o estado, pois a não permanência das populações no meio rural, aumentaria ainda mais o fluxo migratório para Natal e cidades da Área Metropolitana. A ampliação do fluxo migratório para Natal e para as cidades circunvizinhas tem como consequência, o aumento dos problemas sociais e ambientais.

O presente trabalho tem como objetivo principal esboçar os aspectos da urbanização do campo, bem como das atividades não-agrícolas no meio rural na Comunidade de Traíras, e fazer um levantamento das condições socioeconômicas, para identificar se vem ocorrendo melhorias na vida da população envolvida nestas novas atividades.

Como aportes metodológicos, a pesquisa é de cunha qualitativa-exploratória, tendo como início a construção do embasamento teórico que explicitem os fenômenos a serem estudados, do mesmo modo utilizou-se de técnicas de coletas de dados através de entrevistas com apoio de formulários. Tais entrevistas foram realizadas em trinta residências de forma aleatória e intencional, para obtenção de dados primários e uma avaliação qualitativa, assim como, observações no local e busca documental nos órgãos públicos que formaram os dados secundários da pesquisa.

A escolha da Comunidade de Traíras, no município de Macaíba, na abordagem deste estudo, levou em consideração os seguintes fatores: em primeiro lugar, ser morador da área e filho de agricultora, conhecendo bem a realidade da área a ser estudada, e diante do exposto a grande identificação da minha parte com a área rural; segundo, promover um diagnóstico socioeconômico da área; por fim, tentar despertar o interesse dos órgãos públicos para a criação e implantação de políticas públicas que venham a contribuir com o desenvolvimento socioeconômico da população local.

Uma nova configuração do espaço rural brasileiro tem demonstrado questões a serem estudadas, como por exemplo, a mecanização da produção agrícola. $\mathrm{O}$ uso de máquinas tem ocupado postos de trabalhos de agricultores braçais, esta troca do trabalhador rural não qualificado pela máquina, juntamente a concentração da terra, tem acentuado as desigualdades sociais no campo e estimulando o surgimento de atividades não agrícolas no meio rural, atividades antes consideradas urbanas tem crescido bastante e se constituído estratégias de sobrevivência e permanência no campo.

Nas últimas décadas observa-se uma melhoria na estrutura rural e instalação de elementos urbanos nas comunidades rurais. Observamos que na comunidade Traíras, como em outras comunidades vizinhas, existem melhorias como: instalação de energia elétrica em todas as residências, abastecimento de água encanada, telefonia pública e residencial, instalação de postos de saúde, escolas com ensino fundamental e médio, bem como o calçamento de algumas ruas e por último o acesso à internet.

Em suma, tais melhorias, juntamente a alguns elementos urbanos e alguns serviços, incentivaram 
a ocupação de pessoas em atividades comerciais e produtivas não-agrícola, trazendo um novo ideário à população rural, evidenciando a urbanização física e ideológica da área em estudo.

\section{O CAMPO SE URBANIZA}

Carlos (1994) nos mostra que o espaço geográfico é resultado de uma articulação entre a sociedade e a natureza, o qual se torna produto humano, social e histórico a partir de que o ser humano modifica e reproduz o mesmo.

A dialética socioespacial produz o espaço geográfico, o qual é formado por interações do homem com a natureza. Para Santos (1997 p. 26) deve se considerar o espaço como um conjunto inseparável em que participa de um lado um arranjo de elementos geográficos naturais e sociais e de outro lado a sociedade em movimento.

Neste contexto de modificação do espaço, do progresso tecnológico e de sua irradiação pelo espaço geográfico, a dinâmica socioespacial vem se tornando cada vez mais complexa, a ponto de ser cada vez mais difícil separar o que é rural do que é urbano. Dentro desta perspectiva se observa uma reestruturação do meio rural e uma significável urbanização do campo em diversas áreas do Brasil.

O espaço rural segundo Marques (2002) citado por Candiotto e Corrêa (2008) corresponde a um meio com características mais naturais, e é produzido a partir de usos em que a terra, aparece como fator principal, tendo como resultado a criação de organizações sociais fortes localmente.

Para Rémy e Voyé (1992) o campo é descrito como paisagens descontinuas, que se alterna entre florestas e habitações isoladas e com funções agrícolas.

Tal como a cidade, também o campo supõe uma dupla definição. Considerado na sua morfologia, o campo surge como oferecendo uma paisagem em que um habitat e uma construção descontínuos se distribuem sobre um pano de fundo de natureza, campos e florestas; os povoados, as aldeias, constituem umas tantas unidades de pequenas dimensões, com habitat compacto ou disperso, separadas espacialmente umas das outras, e mais ou menos afastadas do pequeno centro que engloba algumas funções mais específicas, destinadas ao uso do conjunto. Na sua significação funcional, o campo surge, além do mais, como lugar a partir do qual se organiza a produção agrícola, sem ser, contudo, mesmo neste domínio, um lugar totalmente autocéfalo, pois está numa relação de dependência mais ou menos marcada em relação a uma entidade exterior que o controle. Assim, existe uma dependência orgânica do campo para com a cidade, a qual se distingue da única referência morfológica. (RÉMY, J.; VOYÉ, L.; 1992. p. 15).

Para Marques (2002 apud CANDIOTTO; CORRÊA 2008) O espaço rural corresponde a um meio peculiar, com características mais naturais do que o urbano, que é produzido a partir de uma variedade de usos nos quais a terra aparece como um fator principal, e tem resultado em criação de organizações sociais de territorialidades intensas.

Logo, Marques (2002) citado por Corrêa; Candiotto (2008) expressa que os elementos definidores do rural são: a baixa densidade populacional e técnica, e o predomínio de paisagens ricas em vegetação e atividades agropastoris, e forte identidade territorial grupal, que busca afirmar o rural como espaço distinto do urbano.

O meio rural que foi considerado por muito tempo pelas ciências sociais como espaços em crise, teve sua desvalorização mais acentuada no período em que o país passava por transformações econômicas e sociais, por volta da década de 1930, momento em que se iniciava a industrialização no Brasil e a discussão sobre a questão agrária girava entorno da crise do café e da grande depressão iniciada com a quebra da bolsa de Nova Iorque em 1929. O país passava por grandes 
transformações, deixando de ser um país de economia e sociedade agrárias, e inserindo-se em um novo arranjo urbano industrial. Naquele momento, o mais importante era o surgimento daquela nova organização urbano-industrial.

Período complicado para o meio rural brasileiro já que toda atenção estava focada na industrialização. "Argumentava-se então que a agricultura brasileira - (...) - seria um empecilho ao desenvolvimento econômico entendido como sinônimo de industrialização do País". (GRAZIANO DA SILVA 2001 p. 7)

Na Europa, a partir de 1960, e no Brasil, somente a partir de 1980 com o início do processo de modernização da agricultura, acompanhado das facilidades do acesso a informações, é que se inicia uma revalorização do espaço rural, é desse momento em diante que estes espaços vêm sofrendo muitas transformações, perdendo seu caráter tradicional com uma única função, a produção agropecuária, e se convertendo em espaços heterogêneos com muitas funções. Tais modificações ocorrem de formas diferenciadas no território brasileiro, consequência da grande área territorial do Brasil.

Segundo Garcia Ramon (1995) apud Locatel (2004), urbanização do campo é um processo que se origina na esfera urbana e apresenta alguns elementos essenciais que englobam aspectos temporais e espaciais. O primeiro elemento desse processo é a perda de população resultado da mecanização das atividades agrícolas, permitindo uma maior produção; o segundo elemento é o uso residencial do espaço rural, a residência secundária e o repovoamento pela imigração permanente de população aposentada para áreas rurais; e o terceiro componente do processo de urbanização do campo.

Para Santos (1997), o espaço humano no campo se torna cada vez mais tecnificado, culturizado e mais trabalhado segundo os ditames da ciência e do capital. Neste contexto de transformação e tecnificação do espaço rural é que Schneider; Conterato (2008) apontam algumas razões para a explicação das mudanças e das formas de ocupação no meio rural, assim como o crescimento da pluriatividade.

A modernização técnico-produtiva caracterizada pelo crescente processo de modernização tecnológica das atividades agropecuárias vem tornando as práticas produtivas no meio rural cada vez mais individualizada, resultando em redução da utilização da mão-de-obra total das famílias rurais. A queda dos rendimentos agrícolas, sendo esta consequência, principalmente do aumento dos custos de produção agrícola, da dependência tecnológica e das políticas protecionistas. As políticas de estímulo às atividades rurais não-agrícolas e contenção das migrações: as atividades não-agrícolas e a pluriatividade das famílias passou a contar com o apoio e o estímulo das políticas públicas para contrapor-se não apenas à queda das rendas no setor agrícola, mas sobretudo, como uma estratégia de "desintensificação" da agricultura buscando-se amenizar os problemas de super produção e os impactos ambientais. Em um cenário onde o desemprego tornou-se um problema estrutural sem perspectivas de resolução imediata, a busca de geração de oportunidades de trabalho e ocupação no meio rural passou a ser concebido entre os objetivos das políticas públicas; e o reconhecimento da importância crescente da agricultura familiar no meio rural.

Estudiosos das transformações atuais do rural começaram a perceber que não só a agricultura familiar tem capacidade de persistir diante da crescente comercialização produtiva e introdução nos mercados, como também, passou a ser principal forma social presente nos espaços rurais dos países capitalistas mais desenvolvidos. (SCHNEIDER; CONTERATO 2008).

O surgimento de novas alternativas de trabalho nos setores de prestação de serviços, construção civil, comércio e área social têm contribuído para manter o morador no campo. A quantidade de empregos não-agrícolas tem crescido bastante a partir da década de 1990. Esta nova configuração tem despertado a atenção de muitos estudiosos (economistas e geógrafos) bem como de instituições, exemplo: EMBRAPA, IBGE e universidades. Evidenciando o surgimento e difusão de novas atividades no campo brasileiro dando a este, novas funções. 
VIANA, J. P. T; SILVA NETO, D. F.; COSTA, A. M.

\section{URBANIZAÇÃO DO CAMPO: ESTUDO DE CASO DA COMUNIDADE}

RURAL DE TRAIIRAS, MUNICÍPIO DE MACAÍBA - RN

\begin{abstract}
A pluriatividade remete a um fenômeno no qual os componentes de uma unidade familiar executam diversas atividades com o objetivo de obter uma remuneração pelas mesmas, que tanto podem se desenvolver no interior como no exterior da própria exploração, através da venda da força de trabalho familiar, da prestação de serviços a outros agricultores ou de iniciativas centradas na própria exploração industrialização em nível da propriedade, turismo rural, agro turismo, artesanato e diversificação produtiva - que conjuntamente impliquem no aproveitamento de todas as potencialidades existentes na propriedade e/ ou em seu entorno (ANJOS 2003, apud MARAFON 2006, p. 16).
\end{abstract}

A pluriatividade tem mostrado uma nova estrutura rural, onde os moradores do campo têm encontrado alternativas, já que, somente as atividades agrícolas não atendiam suas necessidades básicas.

Na visão de Graziano (2001) apud Candiotto e Corrêa (2008) está acontecendo uma urbanização física do campo, decorrente da inserção de novas atividades econômicas. As novas atividades econômicas não agrícolas ligadas à prestação de serviços diversos tem dado ao campo novas funções.

As transformações no campo não implicam apenas em modificações no espaço físico, não modifica apenas a paisagem, mas também o cotidiano da população, o modo de vida e as relações sociais como mostram Locatel 2004.

O modelo de vida urbano, presente no campo, implica em infraestruturas básicas e em outros sistemas de valores. As infraestruturas básicas urbanas, mais comuns, são a eletricidade, o gás (butano), acompanhados pelo automóvel, a televisão, os eletrodomésticos, o mobiliário 'moderno', o que implica em novas exigências relacionadas aos serviços. (LOCATEL, 2004, p. 172).

Santos (1989) nos mostra que, elementos como o revestimento das ruas, sejam ele calçamento de pedras ou revestimento de asfalto; água encanada e esgotos; e energia elétrica, são componentes típicos de áreas urbanas e são mencionados como "equipamento urbano de base".

Diante do que expõe Locatel, juntamente a ideia de equipamento urbano de base de Santos, podemos dizer que a urbanização do campo é uma realidade na comunidade estudada, já que encontramos toda esta infraestrutura básica na comunidade de traíras como também se observa novos costumes, novos pensamentos e novos hábitos. A chegada de tais elementos urbanos é decorrência do desenvolvimento tecnológico, e com isso o aumento da mobilidade de pessoas e bens.

O sistema de valores é o conjunto de costumes e hábitos vinculados ao modo de vida urbana, tais como as músicas, danças, tipos de festas. De um modo geral, o lazer baseado na cultura citadina, como por exemplo, os hábitos alimentares e as relações pessoais. Junto a isso, surge uma nova forma de consumo. Deste modo, se proliferam novos formatos de pensamentos difundidos pela cidade, entre a população rural, sendo os jovens os responsáveis ativos por uma rápida assimilação de coisas e representações vindas da cidade (LEFEBVRE, 1969 apud LOCATEL 2004).

A urbanização a partir de um sistema de valores é tão forte que chega a ser considerada "a urbanização ideológica como mais ampla e eficaz em relação à urbanização física" (RUA 2005 apud CANDIOTTO; CORRÊA 2008, p. 221).

Um dos fatores que contribuem para urbanização do campo é a evolução tecnológica e o avanço dos meios de comunicação. Tais avanços diminuem os custos do fluxo de pessoas, mercadorias e informações, permitindo que cada vez mais indivíduos, venham a usufruir do acesso maior a informação. 
VIANA, J. P. T; SILVA NETO, D. F.; COSTA, A. M.

\section{URBANIZAÇÃO DO CAMPO: ESTUDO DE CASO DA COMUNIDADE}

RURAL DE TRAÍRAS, MUNICÍPIO DE MACAÍBA - RN

Como consequência do aumento da mobilidade, propiciado pelos avanços tecnológicos, ocorre a facilitação das relações entre territórios cada vez mais extensos e mais distantes entre si. Isso corre, por um lado, com a redução dos custos (dinheiro e tempo) dos deslocamentos de pessoas e mercadorias. Por outro lado, o desenvolvimento dos meios de difusão (principalmente a televisão e o telefone) permite que os indivíduos e os grupos tenham acesso a um enorme rol de informações de diversas procedências, sem mover-se do lugar. Assim, a proximidade física não é mais o elemento principal para a formação das redes de relações necessárias para a vida no campo. Da mesma forma, não é mais indispensável, como era antes, viver na cidade para usufruir as vantagens sociais e culturais disponíveis em uma sociedade. (REMY e VOYÉ, 1976 apud LOCATEL 2004, p. 173).

Podemos concluir que Traíras, vem passando por transformações espaciais, através do que podemos chamar de urbanização física do espaço e acesso a infraestrutura básica, do mesmo modo a facilidade ao acesso a informações tem feito com que os moradores adquira novos modos de vida e novas relações sociais, e até mesmo perdendo um pouco de sua cultura local e absorvendo uma cultura cada vez mais globalizada.

\section{MACAÍBA E COMUNIDADE TRAÍRAS: BREVE HISTÓRICO E CONTEXTUALIZAÇÃO ESPACIAL}

A colonização da capitania do Rio Grande do Norte obedeceu aos moldes do sistema português de concessão dos direitos de exploração aos donatários. Mas os beneficiários nunca conseguiram ocupar as terras. Sendo retomada a concessão à coroa portuguesa e o processo de colonização iniciada com a construção da Fortaleza dos Reis Magos e a fundação de Natal. Os centros de povoamento se sustentavam na produção do açúcar, iniciada com o Engenho de Cunhaú, em Canguaretama e o Engenho Potengi também chamado por Ferreiro Torto, Macaíba/RN.

No início do século XVII, precisamente em 1614, o Capitão Francisco Rodrigues Coelho, recebeu algumas datas de terra, que deram origem ao Ferreiro Torto, e ergueu o Segundo Engenho da Capitania do Rio Grande: o Engenho Potengi. Em meados deste mesmo século, Macaíba ainda não existia como unidade político-administrativa. Somente os sítios do Ferreiro Torto, Uruaçu e Jundiaí eram habitados por portugueses, mestiços e índios que trabalhavam na agricultura rudimentar, exploração do engenho e pecuária.

No século XVIII, entre 1780 e 1795, surgi o primeiro nome da vila emergente, "Coité". Este nome foi dado pelo Coronel Manoel Teixeira Casado. O nome da povoação que começava a crescer na orla do Rio Jundiaí, veio da árvore Coité que se destacava entre os vegetais que cobriam o chão da região. Árvore de grande fruto não comestível, que servia para fazer vasilhas, muito vista em toda a vila.

Em decorrência de acontecimentos externos que impulsionaram o ciclo do algodão e a própria mobilização comercial, Coité foi bastante favorecida nos meados do século XIX, por encontrarse localizada numa área estratégica, para a época, Coité beneficiou-se de toda situação que envolvia a comercialização e o transporte de algodão. Eram tempos difíceis para o setor de transportes, sendo muito difícil o transporte de qualquer tipo de mercadoria ou mesmo passageiros para o exterior ou mesmo trazê-los para a capital.

Macaíba, cidade localizada às margens do Rio Jundiaí, é berço de muitos filhos ilustres, dentre eles Auta de Souza, poetisa; seu irmão Henrique Castriciano de Souza (ex-vice-Governador do Estado, Fundador da Escola Doméstica de Natal e da Academia norte-rio-grandense de Letras); Dr. Octacílio Alecrim, escritor e um dos mais respeitados juristas do seu tempo; Augusto 
Severo de Albuquerque Maranhão, professor, político, aeronauta inventor do dirigível balão PAX; Alberto Frederico de Albuquerque Maranhão, ex-governador do Estado por dois mandatos; Augusto Tavares de Lyra, ex-governador, ex-ministro de Estado do governo Afonso Pena e um dos maiores oradores do Brasil.

Como pontos históricos, destacam-se o Solar do Ferreiro Torto, a Matriz de Nossa Senhora da Conceição, a Capela de São José (a mais antiga da cidade), o Solar da Madalena, a Capela da Soledade, casa onde nasceu Henrique Castriciano, Obelisco Augusto Severo, Casarão dos Guarapes e Solar Caxangá.

Macaíba está situada na zona Litoral Oriental, na microrregião de Macaíba, com área total de 512,49 $\mathrm{km}^{2}$ equivale a $0,92 \%$ do território estadual. Limita-se com os municípios de São Gonçalo do Amarante e Ielmo marinho a Norte, Vera Cruz e São Jose de Mipibú a sul, Natal e Parnamirim a Leste e São Pedro e Bom Jesus a Oeste (Figura 1). A sede do município está situada a uma altitude de 11 metros em relação ao nível do mar, e apresenta coordenadas $05^{\circ} 51^{\prime} 30^{\prime \prime}$ de latitude sul e $35^{\circ}$ 21 ' 14" de longitude oeste. Distante da capital $14 \mathrm{~km}$ em linha reta. Seu acesso partindo da capital do Estado é feito por duas rodovias federais pavimentadas, através da BR 226 pela zona Oeste de Natal, e pela BR 304 passando pelo município de Parnamirim.

Figura 1. Local da realização do estudo

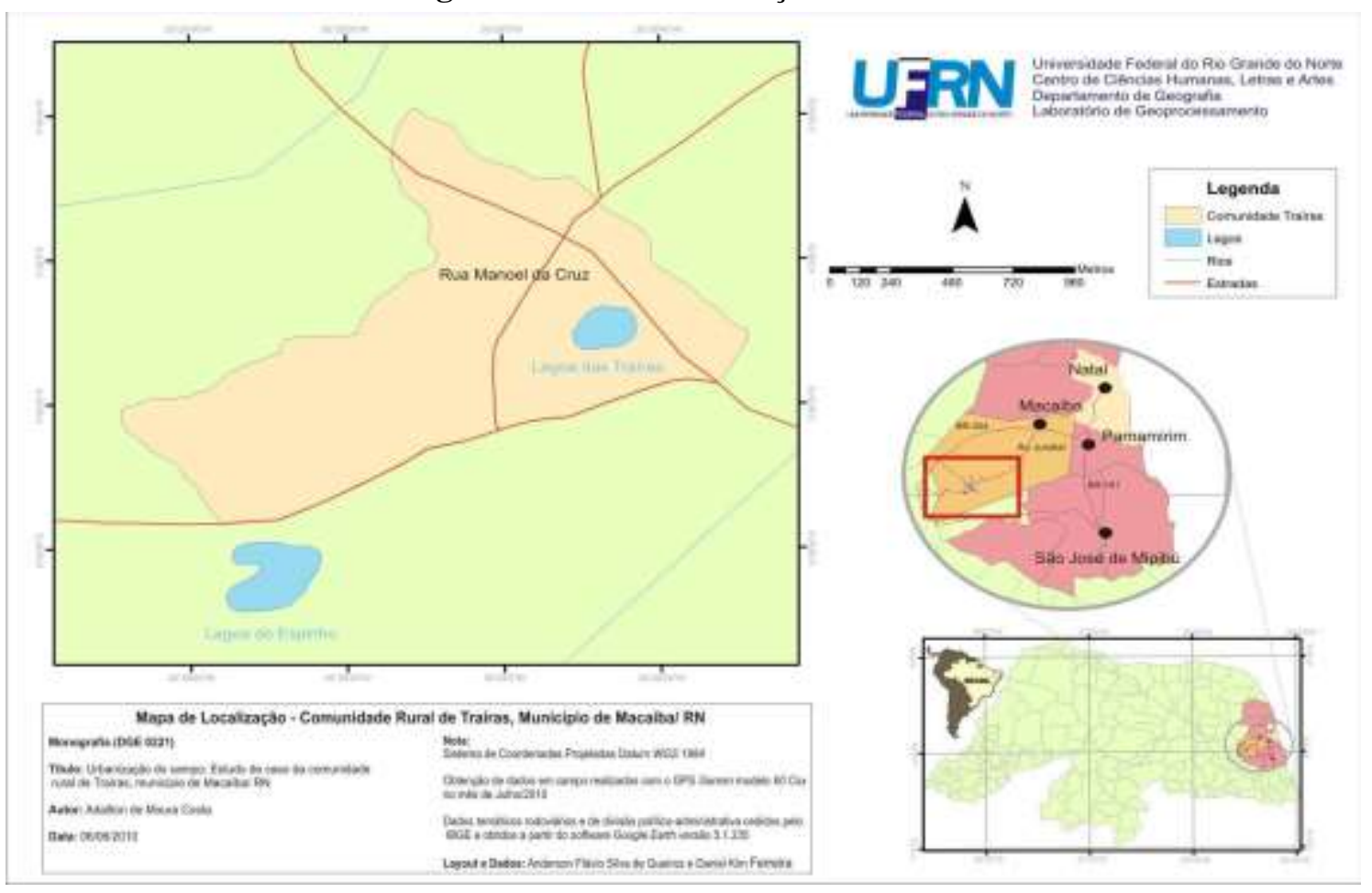

Fonte: COSTA, 2019

Traíras está localizada na zona rural de Macaíba, distante $30 \mathrm{~km}$ da sede municipal, o acesso a comunidade partindo de Macaíba é feito a partir da RN 160 até a comunidade de Cana Brava, e segue por uma rodovia asfaltada até Traíras. A comunidade conta com uma infraestrutura básica de água encanada, luz elétrica, telefone residencial e telefones públicos espalhados em locais estratégicos da comunidade, sendo sua principal rua asfaltada.

A comunidade conta com uma população de aproximadamente 3.000 pessoas (segundo informações de agente de saúde da comunidade), espalhadas por onze ruas que são elas: Nossa Senhora Santana 
(Figura 05), Leão do Norte, Manoel da Cruz, Teófilo Nóia, Genésio Quirino, Hermes Marinho, Luiza Cordeiro, Luiza Florêncio, Santa Cecília, Antônio Mulato e Paulo Severiano. Para atender a população local a comunidade dispõe de uma variedade de comércios de pequeno porte que vai desde pequenas mercearias a depósitos de material de construção. A população de Traíras ainda conta com lojinhas de variedades, móveis e assistência mecânica a motos, já que este é um meio de transporte muito utilizado nas comunidades rurais de todo o Nordeste.

O acesso a luz elétrica, água encanada, ruas asfaltadas, coleta de lixo, posto de saúde e escolas. Tais serviços considerados atualmente primordiais para uma vida digna, em décadas passadas eram privilégios das áreas urbanas. Exemplo disso, na comunidade em estudo, em tempos passados o uso de animais para o transporte de pessoas mercadorias e água era muito comum. Atualmente o uso de animais é muito pequeno, e a comunidade conta com um número razoável de motos e automóveis. As fotos a seguir mostram o mesmo local diferenciando as construções, a rua asfaltada e os meios de transporte (Figura 2).

\section{Figura 2. Construções em diferentes realidades e contextos}

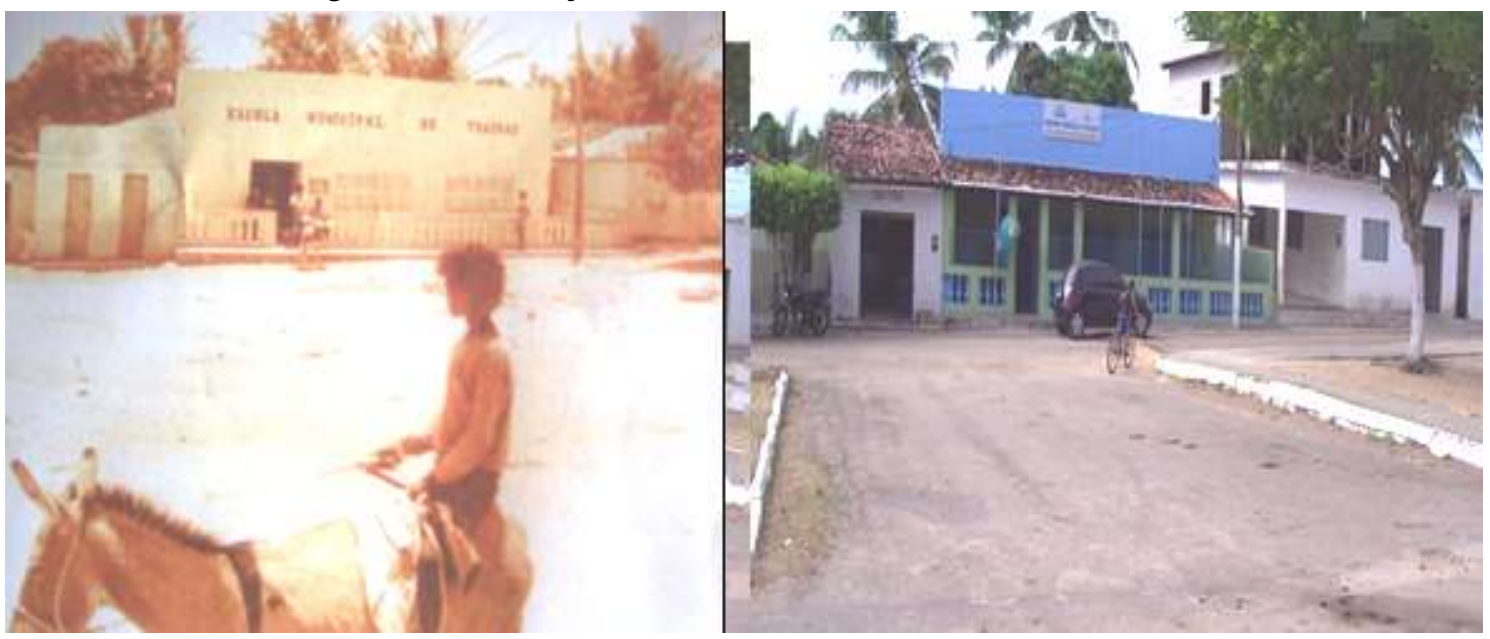

Fonte: COSTA, 2019

O fluxo de pessoas entre Traíras e a sede do município é feito através de vans cadastradas na Secretaria de Transportes do município. O intervalo de horário entre dois veículos varia de trinta a quarenta minutos, iniciando-se às cinco horas da manhã partindo de Traíras, e o último partindo de Macaíba destino Traíras às dezoito horas. Além de 1 (um) ônibus que sai da comunidade com destino a Natal diariamente às cinco horas e retornando às quatorze horas.

\section{A REALIDADE DO ESPAÇO EM ESTUDO}

A pesquisa realizada na comunidade nos mostrou que, a população de Traíras mesmo situando-se na zona rural do município, apenas $22 \%$ dos entrevistados tem como ocupação principal, a agricultura. Vale salientar que, deste total, parte são agricultores que trabalham como diaristas. A agricultura têm sido em muitos casos desenvolvida juntamente a outras atividades para complementar a renda familiar, através de pequenas lavouras de milho, feijão e mandioca no sistema de lavoura consociada como afirma um entrevistado, "Trabalho aqui na borracharia e planto mandioca, milho e feijão, por que não dá para viver só da agricultura" (entrevistado). As diversas atividades como prestação de serviço, comércio, setor público, ocupam $39 \%$ dos entrevistados, enquanto 39\% dos entrevistados são aposentados, como mostra a Figura 3. 
Figura 3. Ocupação da população e renda familiar

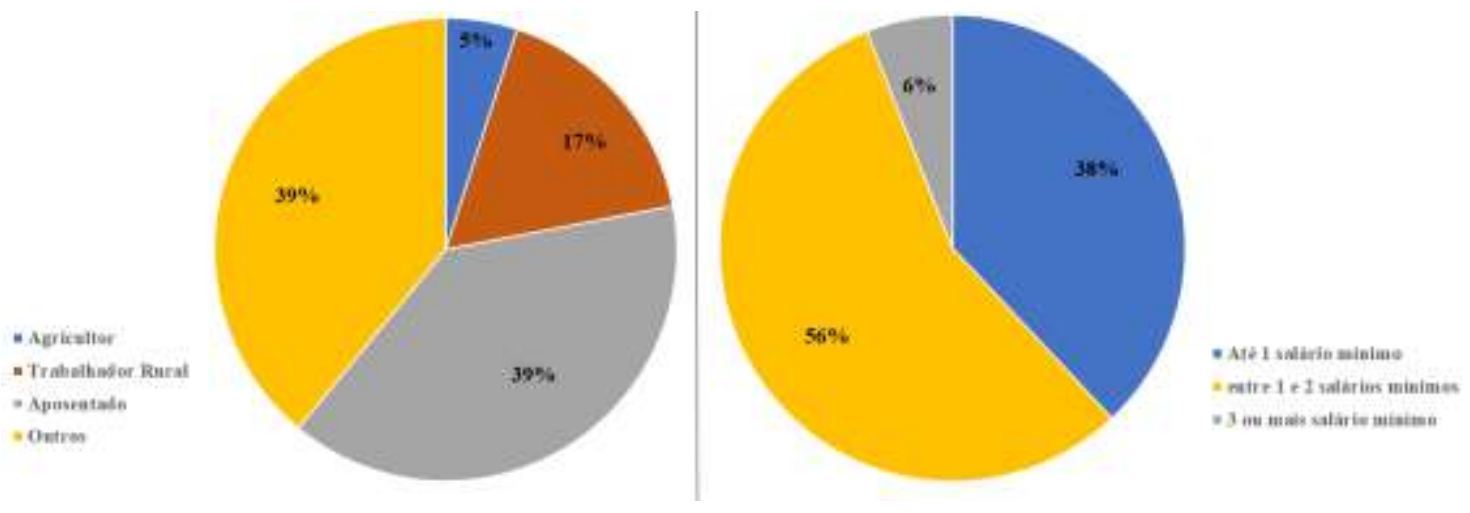

Fonte: COSTA, 2019

A pesquisa nos revela que a renda familiar de $38 \%$ dos entrevistados é de até um salário mínimo, entre estes estão principalmente os trabalhadores com baixa instrução escolar e, ocupados em atividades agrícolas e não agrícolas sem vínculos empregatícios.

O segundo grupo é composto por pessoas que desenvolve junto à agricultura outras atividades, seja o comércio, serviços ou ocupações no setor público (ASG, merendeiras, vigias), os aposentados e os que trabalham fora da comunidade.

Dessa maneira, possui uma parcela menor da população com apenas $6 \%$ dos entrevistados com renda igual ou superior a três salários mínimos, estes são comerciantes, produtores rurais possuidores de terra e implementos agrícolas, e até mesmo caminhões para transportar suas mercadorias. A Figura 3 representa esta distribuição da renda familiar entre os moradores de Traíras.

Considerando-se a habitação e o estado dos domicílios como elementos importantes na análise das condições de vida das pessoas. Notamos que as residências se encontram em bom estado de conservação e poucas casas em estado regular de moradia, todas são construídas em material de alvenaria e cobertura de telhas ou até mesmo lajeadas, pisos cimentados, com revestimentos cerâmicos. Não detectamos nenhuma residência com piso de chão batido. O questionamento sobre o abastecimento de água e energia elétrica nos revelou o fato de que todas as residências dispõem de luz elétrica e água encanada. $\mathrm{O}$ abastecimento e distribuição da água são feitos pela Companhia de Águas e Esgotos do Rio grande do Norte - CAERN. O acesso a estes serviços é feito de forma regular. Ainda dispõem de coleta de lixo que é feita duas vezes por semana, no entanto, a comunidade como um todo não dispõe de rede geral de esgotos, os esgotos são lançados em fossas rudimentares.

Com relação aos serviços sociais, a maioria dos entrevistados considera os serviços de saúde de boa qualidade, sendo relacionados pelos entrevistados os serviços médicos básicos, odontologia e exames laboratoriais, sendo feitos na própria comunidade. Os casos de alta complexidade são levados ao Hospital Regional de Macaíba, através de uma ambulância que está 24 horas a disposição da comunidade.

O acesso à educação, atualmente, é bastante facilitado já que a comunidade dispõe de uma creche, uma escola de ensino fundamental, e uma escola de ensino fundamental e médio. As maiores dificuldades com relação à educação, diz respeito ao ensino médio, sendo este o mais afetado por falta de professores, este foi o principal problema com relação à educação, segundo os entrevistados. Porém, apesar da disponibilidade de instituições de ensino em Traíras, os níveis de escolaridades ainda são baixos, como mostra a Figura 4. 
Figura 4. Escolaridade da população da Comunidade de Traíra

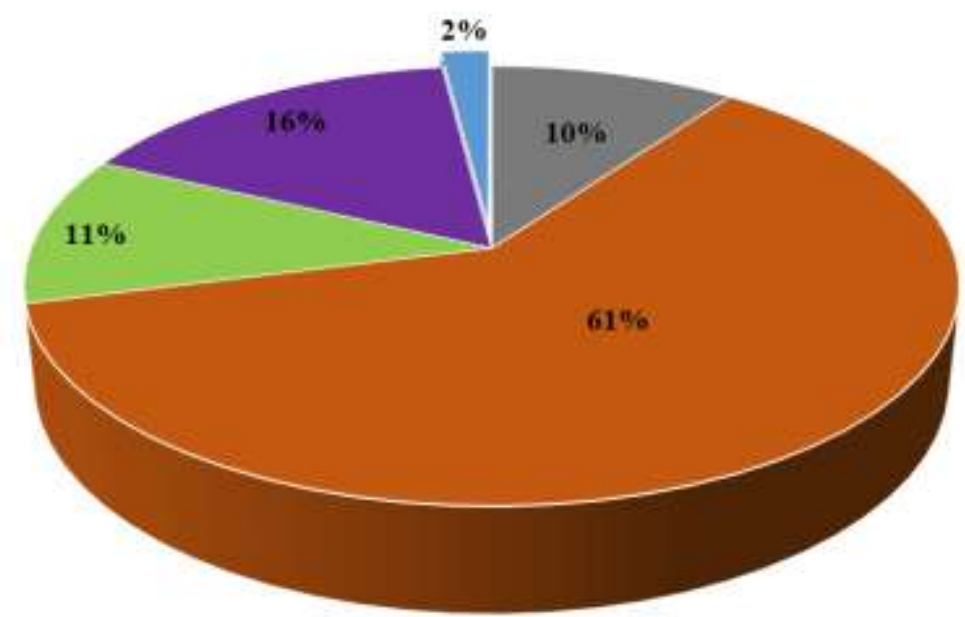

Fonte: COSTA, 2019.

Com base na Figura 4, podemos identificar, que mais da metade da população entrevistada, não possui ensino fundamental completo, $12 \%$ dos entrevistados não tem instrução formal e apenas $4 \%$ tem ensino superior.

Segundo Schneider (2003) o aparecimento da expressão "agricultura familiar" surgiu no conjunto brasileiro a partir da metade da década de 1990. Neste período, ocorreram eventos que tiveram um impulso social e político muito expressivo no meio rural, especialmente na região Centro-Sul. De um lado, no campo político, a adoção da expressão parece ter sido encaminhada como uma nova categoria-síntese pelos movimentos sociais do campo, encabeçados pelo sindicalismo rural ligado à CONTAG (Confederação Nacional dos Trabalhadores na Agricultura). Em meados dos anos de 1990, assistiu-se a uma verdadeira efervescência desses movimentos, que produziram inclusive formas de manifestação política que perduram até hoje, como é o caso dos eventos anuais em torno do "Grito da Terra".

Diante dos desafios que o sindicalismo rural enfrentava nesta época (impactos da abertura comercial, falta de crédito agrícola e queda dos preços dos principais produtos agrícolas de exportação), a incorporação e a afirmação da noção de agricultura familiar mostrou-se capaz de oferecer guarida a um conjunto de categorias sociais, como, por exemplo, assentados, arrendatários, poceiros, integrados às agroindústrias, entre outros que não mais podiam ser confortavelmente identificados com as noções de pequenos produtores, ou, simplesmente, de trabalhadores rurais.

As afirmações da agricultura familiar no cenário sociopolítico brasileiro estão relacionadas à legitimação que o Estado the conferiu ao criar, em 1996, o PRONAF (Programa Nacional de Fortalecimento da Agricultura Familiar). Esse programa, estabelecido como resposta às pressões do movimento sindical rural desde o início dos anos de 1990, nasceu com a finalidade de fornecer crédito agrícola e apoio institucional às categorias de pequenos produtores rurais que encontravam sérias dificuldades de se manter na atividade.

Podemos destacar que a agricultura familiar tem sido de grande importância na produção de gêneros alimentícios, chegando ao ponto de algumas culturas como: as culturas do fumo, mandioca e feijão, despontam como quase que exclusivas da agricultura familiar. Chamam a atenção também os percentuais alcançados na pecuária de pequenos animais como suínos e aves/ovos e, até mesmo o leite de cabra que no nosso estado tem sido incentivado pelo governo estadual através da compra para o Programa do Leite. 
Em Traíras, a agricultura familiar tem sido incentivada através do Pronaf, com a concessão de crédito aos trabalhadores rurais, do PAIS (Produção Agroecológica Integrada e Sustentável) projeto do Ministério de integração, que consiste no desenvolvimento econômico e sustentável, através da produção conjunta da produção de olerícolas e aves.

Traíras tem sido beneficiada por projetos de apoio ao agricultor familiar, e tais incentivos vem melhorando a renda dos agricultores e diminuindo as desigualdades sociais na comunidade, trazendo a esta uma nova realidade socioeconômica. Tais melhorias são percebidas a partir de que o agricultor com uma renda melhor passa a ter um consumo diferenciado. Isto é percebido através de suas residências e todo o aparato tecnológico que sua renda lhe permite obter.

\section{CONSIDERAÇÕES FINAIS}

Através da realização do trabalho foi possível observar mudanças espaciais, econômicas e sociais ocorridas na comunidade rural de Traíras. As transformações ocorridas na comunidade não são particularidade dela, já que tais transformações vêm ocorrendo em diversos pontos do País.

Notamos que a urbanização Ideológica da população local é decorrente principalmente do avanço tecnológico, que tem levado informação até aos locais de mais difícil acesso do planeta, seja através do rádio, televisão ou internet. A facilidade ao acesso à informação e também de adquirir o aparato tecnológico que facilite a vida tem sido um dos fatores da urbanização, trazendo à população local fragmentos de uma cultura global e até mesmo perdendo um pouco da cultura local já que na comunidade não são mais realizadas festas que ocorreram em outras épocas como: o Boi de Reis, o Pastoril, o João redondo e o forró de sanfona. Observamos novos hábitos, novos costumes, novas formas de pensar, e estes são mais facilmente absorvidas pelos os jovens.

Outro fator da urbanização é o uso residencial do espaço rural, a residência secundária e o repovoamento pela imigração permanente de população aposentada para áreas rurais é mais um componente do processo de urbanização do campo. Este uso do espaço rural como residências secundárias e a imigração de retorno da população aposentada para estas áreas, traz um novo ideário e novas exigências, modificando o espaço, com isso a população local começa a absorver tal modo de vida, e o campo passa a ter novas funções.

Partindo da ideia de transformação do espaço rural, podemos destacar que é cada vez maior o número de pessoas ocupadas em atividades não-agrícolas como também o surgimento de famílias pluriativas, já que, somente os rendimentos adquiridos dentro da unidade produtiva familiar não têm proporcionado o desenvolvimento socioeconômico esperado para se ter uma vida digna. Mas, em contrapartida, o estado tem desenvolvido medidas de incentivo à agricultura familiar com projetos como o Pronaf e o PAIS.

Observa-se a melhoria nos serviços básicos e infraestrutura, proporcionados por parte do poder público. Tais melhorias têm mantido a população na comunidade e trazido novos habitantes para a área. Todavia, o que mais tem preocupado a população local é a falta de emprego na própria comunidade, sendo a economia local, movimentada em grande parte por rendas provenientes das aposentadorias. Outro fator preocupante é a falta de acesso a qualificação profissional. Mas estas deficiências têm sido amenizadas com a facilidade dos transportes. Por fim, detecta-se a falta de lazer para as famílias, haja visto que as alternativas de lazer se resumem ao ginásio, as quadras e aos bares, não tendo nenhum outro tipo de diversão.

Podemos então concluir que mesmo com as dificuldades que ainda existe no meio rural brasileiro, têm sido válidos os incentivos à melhoria das condições de vida e a fixação das populações no campo. 


\section{REFERÊNCIAS}

CANDIOTTO. Luciano Zanetti Pessoa; CORRÊA. Walquíria Kruger. Ruralidades, urbanidades e a tecnicização do rural no contexto do debate cidade-campo. Revista de geografia agrária, Campo-território, Uberlândia, $\quad$ v.3, $\quad$ n. $\quad 5, \quad$ p. $\quad$ 214-242,fev.2008.Disponível, $\quad$ em: http://www.campoterritorio.ig.ufu.br/viewarticle.php?id=141. Acesso em 27 jul.2020.

CARLOS, Ana Fani Alessandri. Cidade: uma perspectiva histórica. In: A cidade. 2. ed. São Paulo: Contexto, 1994.cap.4, p.56-66.

FELIPE, José Lacerda Alves; CARVALHO, Edílson Alves de. Economia do Rio Grande do Norte: estudo geo-histórico e econômico. João Pessoa: Grafset, 2002. 1 mapa.

FOTOGRAFIA do Solar Ferreiro Torto. 2008. 1 fotografia, color. Disponível http:// balaio vermelho. blogspot. com/ 2008/ 05/ 01_ archive. html. Acesso em 20 de abril de 2020.

GRAZIANO DA SILVA, JOSÉ. O que é questão agrária. 4a reimpr.2.ed. 1993. São Paulo: Brasiliense, 2001- (Coleção primeiros passos; 18).

GRAZIANO DA SILVA, JOSÉ. O Novo Rural Brasileiro. Revista nova economia, Belo Horizonte. n.7, v.1,1997. Disponível em http://www.eco.unicamp.br/ nea/ rurbano / textos/ congrsem/ rurbano7.html.

INSTITUTO DE DESENVOLVIMENTO SUSTENTÁVEL E MEIO AMBIENTE. Perfil socioeconômico do município de Macaíba. Disponível em: http://www.idema.rn.gov.br/contentproducao/aplicacao/idema/socio_economicos/enviados/perfil_munici pio. Acesso em 20 de agosto de 2020.

LOCATEL, Celso Donizete. Modernização da agricultura, políticas públicas e ruralidades: mudanças e permanências na dinâmica rural das microrregiões de Jales e de Fernandópolis - SP. Tese de Doutorado apresentada ao Programa de Pós-graduação em Geografia da Universidade Estadual "Júlio Mesquita Filho”, Campus de Presidente Prudente, 2004.

MARAFON, Gláucio José. Agricultura familiar, pluriatividade e turismo rural: reflexões a partir do território fluminense. Revista de geografia agrária, Campo-território, Uberlândia, v. 1, n. 1, p. 17-60, fev. 2006.

RÉMY, Jean; VOYÉ, Liliane. A cidade: rumo a uma nova definição?. Lisboa: Afrontamento. 1992.

RIO GRANDE DO NORTE: Macaíba. Disponível em: http://www.ibge.gov.br/ cidadesat/ topwindow.htm?1. Acesso em 27 maio 2020.

SANTOS, Milton. Morfologia do tecido urbano. In: Manual de Geografia urbana. 2. ed. São Paulo:Hucitec, 1989. cap. 13, p.186-194.

O espaço: sistemas de objetos, sistemas de ação.In: .A natureza do espaço:técnica e tempo,razão e emoção.3ed.São Paulo:Hucitec,1999.cap.2,p.50-71

SCHNEIDER, Sérgio. Teoria social, agricultura familiar e pluriatividade. Revista brasileira de ciências sociais - v. 18 n. 51 , p. 99-121, fevereiro. 2003

SCHNEIDER, Sérgio.; CONTERATO, Marcelo Antônio. Transformações agrárias, tipos de pluriatividade e desenvolvimento rural: considerações a partir do Brasil. In: Guillermo Neiman; Clara Craviotti. (Org.). Entre el Campo y la Ciudad Desafíos y estrategias de la pluriactividad en el agro. Buenos Aires: Ciccus, 2006.

SCHNEIDER, Sérgio; RADOMSKY, Guilherme F.W. A pluriatividade e as transformações do mercado de trabalho rural gaúcho: estudo de caso no município de Barão. 2003.62p.. Instituto de Economia UNICAMP. 